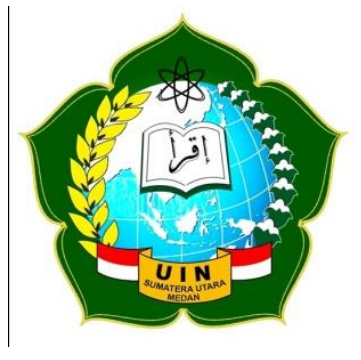

VISION JOURNAL

$\underline{\text { http://jurnaltarbiyah.uinsu.ac.id/vision }}$

\title{
THE PYGMALION EFFECT: HOW EXPECTATIONS INFLUENCE TEACHERS' GRADING DECISION MAKING
}

\author{
Nisrina \\ Universitas Gajah Putih \\ Email: nisrinacance@yahoo.com
}

\begin{tabular}{|l|l|}
\hline Keywords & Abstract \\
\hline Keywords: Teachers' & $\begin{array}{l}\text { This study investigated teachers' expectation for students that } \\
\text { lead to the choice of assessment types and the considered } \\
\text { Factors, Grading Decision } \\
\text { factors in grading decision making. Two teachers from } \\
\text { different public senior high school were selected. The } \\
\text { phenomenon where the positive teaching expectations } \\
\text { deliberately lead to high student achievement (Pygmalion } \\
\text { effect) is found in this study. The results show that positive } \\
\text { teachers' expectation for students will be reflected through } \\
\text { their positive body language and give learning instruction } \\
\text { more challenging for those who can fulfill their expectation i.e } \\
\text { high achievement students. The expectations are dealing with } \\
\text { students' active participation the class and manner or attitude. } \\
\text { Henceforth, teachers give more concern in applying informal } \\
\text { assessment in grading students' achievement in which process } \\
\text { is more concerned instead of result. In addition, their } \\
\text { expectations for students are used in considered factor in } \\
\text { grading students' achievement that is reflected in the report } \\
\text { cards. Low achievement students could receive } \\
\text { disadvantageous learning condition because of teachers' } \\
\text { expectation influencing their performance in a negative way, } \\
\text { as grant their grade in report cards does not measure their real } \\
\text { achievement. }\end{array}$ \\
\hline
\end{tabular}

Faculty of Tarbiyah and Teacher Training, 1st Floor

Jalan Willem Iskandar Psr V Medan, 20731

Telp. 061- 6622925 - Fax. $061-6615685$ 


\section{INTRODUCTION}

Before teachers enter the class, even, they have formed expectancies about how the class runs. It goes hand in hand with their expectation about students' achievements. The expectation about students' achievements is formed based on their knowledge about their students through the activity the day before. Once teachers set the expectation, they tend to attain the condition what is expected. Thus, they treat the students to perform better and it leads to students' high achievement. In education domain, this is called Pygmalion effect (Chang, 2011).

The significant note needs to be considered about Pygmalion is that it creates an obvious change in surface of what is going on. When teachers expect students to achieve more, they treat them in positive ways (Wang and Chai, 2016). For example, teachers tend to do more positive body language toward students that they expect to perform well. Give them more challenging instruction, offer chance to explain to their friends, and provide more feedback. All the teacher's treatment will lead to the what is expected by teachers. If these treatments have the same rhythm every teaching practice, it will form students' achievement as what is expected because they have high motivation and prejudice toward learning (Niari, Manousou and Lionarakis, 2016).

Regarding to the students' achievement that is reflected into two categories, those are academic and non-academic grades (Isnawati and Saukah, 2017). Many factors come into the play when it comes to decide students' grade. Isnawati and Saukah (2017) claimed that the factors that boosts decision making for academic grades obtained from formal and informal assessment. Furthermore, non-academic grade factors such as students' effort and behavior are taken for consideration. However, factors that are in charge in students' grade is not only come from the students but also obtain from the teachers. Teachers' have set kind of assessment applied, factors that will be scored and how assessment will be administered. These kinds of factors are connected with achievement expected by the teachers. For example, teachers have set expectation about particular students, it will lead to the assumption that the assessment applied will be based on the expectations set. It probably makes students expected to perform well will obtain better grade.

In contrast, the low achievement students could get disadvantageus learning situation because of this expectation. For low achievement students, they received discrimination about leaning instruction did not obtain good body language. This kind of situation would hinder their capability because expectation had been set by the teachers. Chang (2011) stated that the 
teachers' expectation could vividly reflected on their behavior to students, thus if the low achiever got negative expectations from the teachers they would be in the area where they could not follow the teaching learning process, in the consequences if the teachers take into account their expectation in grading decision making, they would be received the score that was not their real attainment.

In sum, previous study had investigated the teachers' expectation for students' achievement (Wang, Chai, 2016). It is important to know deeper, the achievement that was reflected in students' report card whether or not either assessment types or factor in considering decision making teachers applied was not to measure students' achievement but to enhanced the teachers' expectation by selecting the assessment types that give advantages for the students who were expected to perform well.

\section{METHOD}

In this study, two teachers were examined to know how their grading decision making was influences with their expectations. The two of them were in different school to make triangulation of data. One of the teachers was from SMA Negeri 1 Takengon, henceforth identified as Teacher 1 . The other was from SMA Negeri 4 Takengon, she was called as Teacher 2.

The two teachers had taught English as in-service teachers for more than four years and had had certification as professional teachers. Background of their education was that graduated from English Language Education at bachelor degree. During their teaching, they also had joined some teacher professional trainings especially related to curriculum implementation that consists of the way to have good assessment in the class. In a week, both teachers had to teach at least 24 hours as the requirement of teacher certification. They taught six classes, each of which has a four-hour meeting in a week. In the other words, they would teach twice a week in particular class.

These two teachers were from two different public junior high schools, however they used same curriculum that was 2013 curriculum. 2013 curriculum demanded teachers to give score for four aspects namely cognitive, psychomotor, affective and religious aspects. Consequently, the form of students' report card of 2013 curriculum divided into four columns, 
those were cognitive, psychomotor, affective and religious aspects with descriptive reports of students' learning.

In order to reveal the two English teachers' expectation and grading decision making in depth, an open-ended interview guide was used as data collection. The interview guide consisted of three sections following research questions; they are 1 teachers' expectation for the students, 2 grading practice and assessment types, 3 factors considered in grading decision making. The interview was retrospective in which they were required to recall what was taken in place when the class run, assessment practice applied and the factors considered in grading decision making. The interview was conducted in their home to attain more relax situation and they answered the real picture of their class without having anxiety be disturbed by their matr and by the situation that drag them to be well-regulated than the reality. It was conducted face-to-face and lasted 50 and 55 minutes. The interviews with these two teachers were recorded and transcribed. The teachers' responses to the interview questions were then coded, classified, analyzed, and interpreted in order to answer the research questions.

The data should not have bias toward research questions; thus, triangulation was necessary to be administered. Besides the data were triangulated through taking two sources of data namely teacher 1 and teacher 2, inter-rater data analysis was done to have same interpretation on the data coded, classified and analysis. Inter rater done by giving recorded and transcribed to the analysts. She is lecturer at Bina Nusantara University at Malang. Result of coded, classified, analyzed and interpreted data got from researcher were transferred separately to give more independent to her to analysis the data then she also gave comment to researcher's result of analysis if there was misinterpretation.

\section{FINDINGS AND DISCUSSION}

\section{Findings}

The results of this study are presented based on the three research questions; those are teachers' expectation about the students, grading practice and assessment types, and factors considered in grading decision making.

\section{Teachers' Expectation about the Students}

Both teachers gave similar answer about their expectation set. Teacher 1 told that she expected how the class run when the lesson plan had already compiled. Because it was English 
subject, she expected students to show their active participation in the class. To achieve that willing, she often put the high expectation to the students. Once there was a discrepancy between expectations and reality, the class seem just for students who had capability in fulfilling their expectation i.e high achievement students. They would become role model in front of the class to answer the question or even just were asked whether or nor all students had already answered all of the question given. They became standard time for the question had already been answered nor not. When they had already answered the questions, they will answer in the front of the class further the high achievers and the group will demonstrate it to the class.

Teacher 2 said that the condition of the class at Takengon drag them to treat the students based on their competency level in negative way. It was hard to run the class that consists of 30 up to 40 students in one class by concerning each students' level competency. Their competency had wide variation. However, she expected the student become the center of the class, it was fine they gave wrong answer but they should involve the class actively. Because of these expectations, teachers treated the students who fulfill their expectations i.e the high achievers would be center of the class and the instruction. Furthermore, teacher 1 claimed that teacher had duty to fulfill standard competence achieved and teachers had expectations about the achievement of the students in particular meeting, thus checking each student follow each instruction and the received all the material transferred would spend too much time.

Teacher 2 also had same opinion, instead of involving all the students in teaching and learning process, she tended to run the class just for the high achiever. This case took a place because they expected student to do fast reaction on what was instructed to them, such as they should rising their hand once teachers asking the students to go in front of the class. Moreover, in condition the class almost dismiss but the learning instruction had not finished yet. Thus, expecting the high achiever will transfer the material after the class and the learning instruction was complete was the best way to accomplish the learning instruction.

Other aspect was about teachers' body language to the students. In this aspect, Teacher 1 tend to give more positive body language to the students that fulfill her expectations. In case the high achiever had had requirement for teachers' expectations about learning instruction, in the same time she gave positive body language through calling their name, not just called as 'you'. To make sure that they followed the class, she would approach to the desk whether or not they 
did the instruction and once they finish the task delivered, they will got smile or nodding from teacher.

Teacher 2 seems did not give different sound. She said that because expectations about the students had already set and those who could fulfill it was the high achievers, she tend to give more positive body language to them. In case they answered the question in front of class she would touch their shoulder and say thank you. In the other occasion, she would motivate them by giving nodding while they answered the questions in front of class. Moreover, the teacher 1 would approach to their chair as a sample of whole class involvement in class activity.

Another aspect was that students' attitude. Teacher 1 nudged the students' behavior would be easy to manage in the class, give nice conduct in mutual interaction. Therefore, these would ease teaching learning process. In the class, one who can make this expectation came true was the high achievement students. She stated that they were easier to control and watched their manner in the class. In addition, they often sat in front of the row, therefore it was easy to control them. Teacher 2 delivered similar answer to this aspect. She stated that it was nice to have class that had students with good disposition because it lavishly wasted the voice either to asking them to be quiet or to follow the instruction.

They shared voice in common, about politeness was important in the class. Thus, they expected students become polite and interact with the teachers with the proper manner. Teacher 1 preferred if students interrupt in given time meaning they followed the class and delivered nice feedback once they were asking to do so. For example, in answering the question or asking questions, students would nicely ask by raising their hand and by using good intonation in speaking. Teacher 1 expected the students would give question to her as result they follow the class and whether or not it was in purpose, the one who executed this expectation was high achievers.

\section{Grading Practice and Assessment Types Used}

Based on the results of the interview with two English teachers about their grading practice and assessment types used, it was found that both teachers had done various grading practices and used different assessment types in order to attain the students' final grades in the report cards. They used both written and oral assessments during the teaching and learning process. Assessments were for individuals or groups depending on the tasks. The time for assessment was during and after the teaching and learning process in a semester. 
Formal assessment involving tests and in the forms of tasks and projects were also administered by the teachers. For formal assessment, Teacher 1 and Teacher 2 gave the students some kinds of written tests, i.e. daily tests, a midterm test, and a final test. The daily tests were done after the students finished some basic lesson units. They were usually done three to four times in a semester. Mid-term and final tests were done once a semester in the middle and at the end of the term respectively.

Types of assessment applied in formal test were varied between the two teachers. Teacher 1 preferred used multiple choices because it was easy to be corrected. In other occasion, she would administer essay test especially in form of fill in the blank or true false. She preferred these all kind of test due to easy to corrected. On the other hand, teacher 2 preferred to fill in the blank test.

Dealing with informal assessment, Teacher 1 and 2 gave the students project for homework for individual/group tasks to get the scores. Teacher 1 usually preferred to give the students writing journal tasks in written. In addition, she commonly gave mini presentation or demonstration. Homework was given after a certain topic was discussed and used for giving the students more exercises at home, it also can be done through taking exercise from the text book. Teacher 2 also had similar activities for informal assessment. However, she gave more various tasks to the students, such as writing descriptive texts completed with pictures, drama projects, and some other projects.

The scores obtained from these tests had to reach the Minimum Mastery Criteria (Kriteria Ketuntasan Minimal/KKM) set by the schools. In this case, the two junior high schools had the same Minimum Mastery Criteria of 70. The students who could not reach the criteria had to take another test to get better scores. The tests taken for the second time by the students were called remedial tests. Teacher 1 usually gave opportunity to have remedial tests for the students who failed to reach 70 just in final tests. In case the students could not reach the minimum criteria after having remedial tests a number of times, the teacher would deliberately increase the students' score henceforth. On the other hand, Teacher 2 did not give the students opportunity to take remedial tests. There were no remedial tests, for some low-achieving students who always failed in reaching the minimum mastery criteria, teachers deliberately increased the students' score to reach the criteria. 
For informal assessment teachers usually considered some criteria although having scoring rubric was unnecessarily true. They only announced orally the instruction to finish the task. For such activities, the teachers commonly gave higher scores than the Minimum Mastery Criteria (Kriteria Ketuntasan Minimal). This was to appreciate the students' effort in doing the tasks and to motivate the students to study harder in the next meeting. Besides, the teachers did so to anticipate poor scores in the written tests.

After various series of assessment through the teaching and learning, at the end of the semester, the scores obtained were calculated for the final grade in the report card. Teacher 1 summed up the scores of homework, tasks and daily tests, and calculated the mean score to get mean of daily scores. The mean of daily scores, the scores of the midterm test, and the scores of the final test were then summed up and divided by three in order to get the final grades in the report cards. Teacher 2 did the same way to get score for cognitive aspect in the report cards. For the scores of informal assessments, Teacher 2 averaged them and considered the average score as the grade for psychomotor aspect in the report cards. On the other hand, teacher 1, observed their daily activeness to get psychomotor score.

It can be summarized that teachers in this study used various grading practices, individual to group work, and also formal and informal assessment in arriving at the final grades in the students' report cards. The assessment types used by the teachers were both formal, involving written tests, and informal assessment.

\section{Factors Considered in Grading Decision Making}

For both teachers, the process of deciding final grades for the students involved some factors. Teacher 1 and Teacher 2 said that students' achievement is the main factor in assigning grades for the students. However, they had different opinions in considering the students' achievement. According to Teacher 1, in assigning the students' grades, the process of learning is the main consideration. For example, when the students get good scores in the test while they are not really good in the process of learning, the scores in the report card will be adjusted. On the contrary, Teacher 2 relied more on the result of informal assessment if there were different scores between tests and project for home work. Besides the students' achievement, both teachers also considered the students' learning effort, study habits, and behavior in assigning grades to the students. They usually gave additional scores to the students who learnt hard and 
had good study habit although the results in the tests were not quite good. This extra score was given to appreciate their learning and motivate them to do better in the future. However, Teacher 1 seem gave extra concern on students' attitude, she believed that study the material could be received through many resources but learn the attitude was the crucial aspects for life.

The students' active participation in learning was another consideration in grading decision making. According to Teacher 1, students who were active in classroom activities were usually good students and their scores in English had been good enough even though the teacher did not give additional scores for their active participation. Teacher 2, moreover, always encouraged every student to participate actively in the classroom activities. Therefore, according to her, it was fair to give her students extra scores for their active participation.

School policy was also said to influence the teachers in assigning the grade for the students. Although both teachers were from two different schools with different conditions, the schools generally required the teachers to give the students grades equal or higher than the Minimum Mastery Criteria. When there were more poor grades in the report cards, the students were at a risk of not being able to go to the next level of education or even at a risk of dropping out of school. According to Teacher 1, it was almost impossible to give the students grades lower than the Minimum Mastery Criteria although the students' performance was poor. So, giving lower grades means discouraging the students to study at the school and there was a risk to have the students drop out of school. The same policy was also applied in the public school where Teacher 2 was teaching. To accommodate such policy and give the students fair grades at the same time, both teachers usually gave more tasks for those poor students before improving their final grades in the report cards.

Finally, grade reporting format based on curriculums also gave a big influence in teachers' grading decision making. Based on the 2013 Curriculum implemented in their school, teachers were required to provide numerical and letter grades as well as description for students' knowledge and skill mastery. In addition, the social and spiritual attitude must be given letter grade with its description. Teacher 2 said that she had to collect as many scores as possible from the students' activities in the classroom. She got the scores not only from tests but also from observing the students' performance and activities. As a consequence, she tried to give the students more various tasks and projects in order to get more information about the students. In 
short, in grading decision making, the teachers in this study considered not only the students' achievement but also other factors such as students' efforts, their study habit, and their active participation.

\section{DISCUSSION}

The results of the current study show that teachers' expectation to the students lead them to instruct the students become more likely as what are expected. Moreover, teachers' expectation to the students who will perform better is accommodated through teachers' instruction by asking them to perform in front the class. By the time goes in one semester the students are led to the what are expected to them and those who could fulfill teachers' expectations are high achievement students. This result is supported by Boser, Wilhelm, Hanna (2014) who state that teachers' expectation on particular students will lead the students to do what are expected to them.

In this study teachers expect students become more active in the class. Once this expectation is fulfilled by particular students in this case, they are high achievement students, the teachers tend to sign the students and keep instructing them to do learning activities by asking them answer the question in front of the class, demonstrate particular topics and explain the learning material for others. This result is supported by Olivia (1991) who states that teachers tend to give differential manner toward some students perceived more competent and put high expectation for them.

These expectations lead teachers' choice in assessment types used. They tend to give assessment more likely in form of informal assessment. Moreover. the factor considering in grading decision making is students' active participation in class. Looking this plot, teachers are unfair in made up their mind about students score and perpetuate students' achievement gap. Workman (2012) concludes in her study that teachers' expectation can plague the education system in which it could significantly influence students' achievement that is reflected in teachers' grading making.

Although it is still debatable whether good score motivates students to achieve better or students' motivation that lead to better score, the teachers' expectations make this vice versa phenomenon runs in the class. They motive the students expected perform better by asking more challenging questions or nudging them by giving more wait time in acquiring certain topic. After 
assessing their task in form of informal assessment they obtain better score than students expected lower achievement. This behavior perpetuates by giving positive gesture and body language for the students expected to perform in given area. Workman (2012) confronts in her study that a small nudge from teacher can significantly affect students' achievement and grant students' score.

Teachers expect students to behave and watch their manner in the class and they treat the high achiever to conduct as what they want. For example, they ask high achiever to sit in front, it makes teachers be able to asking some questions and students rudely answer is unnecessary true. In this case, they actually do not give a chance to low achievers to answer the question because teachers estimate they will not be able and run out time to complete learning activities in one single meeting. This could happen because teachers gauge the student's competence based on the previous meeting (Workman, 2012).

Low achievement students consequently receive disadvantage affect about this phenomenon. They just do not have a chance express what they are able to do. Teachers have differentiated low achievers by putting low expectation for them, providing tiny feedback on their wrong answer or giving less positive gesture. Teachers show tendency in discrimination on the student through their expectation (Boer, Timmermans and Werf, 2018) The observed conduct are to call high achiever more often, to provide more feedback for low achiever, perhaps, but in class the high achiever got because they seek it, to spend less time in approaching low achiever and to allow low achievement students to sit at back of the class where they can be isolated.

Moreover, for low achiever, teacher expectation that lead to the types assessment their choose i.e students' active participation in class and the factor considered in grading making give them disadvantages affect. The assessment types choose does not measure their capability. At grant, factor considered in grading making i.e students' politeness or students' willingness to study cannot be expressed. If teachers maintain their expectations in semester or perpetuate in next semester, it will make the students' achievement gaps wider (Workman, 2012) and low achievers take more disadvantageous because grades can serve more useful functions for the students' learning and future life.

Overlapping of score may lead in the area of psychomotor affective and cognitive aspects. Teachers' considered factors in grading i.e student active participation, willingness to study and attitude are in the area of psychomotor and affective, however, these factors are used 
in making up their mind in the area of cognitive. Isnawati and Saukah (2017) revealed the phenomenon in their study that all factors in grading decision making are prior to the cognitive score. In the other word, teachers seem blend all of students' achievement whether in form of cognitive, affective or psychomotor in to one score although in the report cards these aspects are separately in table. Teachers use of Minimum Mastery Criteria or in Bahasa KKM is for cognitive factor, thus blending all of learning achievement for it is abundant to be administered and hinder the real achievement attained by students.

\section{CONCLUSIONS AND SUGGESTIONS}

It can be concluded that while both teachers conduct a variety of grading practices and types of assessment in the classroom, non-achievement factors also play an important role in their decisions for the students' final grades. Influenced by their expectation for students that will perform as what expected to them, teachers set learning instructions seem just for high achievement students due to their capability in fulfilling teachers' expectation. Teachers' expectations is dealing with students' active participation in class, attitude and competence. In addition, all of these expectations are executed by high achievement students. These expectations lead not only the teachers in choosing assessment types used in the class but also teachers' considered factors in decision making. They tend to administer informal assessment such as students' project by writing their journal or making clipping for specific topics because this type of assessment can boost students' active participation. In addition, these expectations will be used as considered factor in decision making. The one take advantage for this is high achievement student because of their capability in fulfilling teachers' expectation. However, for low achievement students, gauged by the teachers, will not be measured their real attainment because it is hindered by teachers' expectation. If the ideal grading decision making based on assessment theory is sought, teachers should measure what is measured without restricted by their expectation since grade is a vivid reflective element in students' achievement and will influence their next education and future life. Joint teacher professional development program is considered pervasive. Teachers are often unaware of the differential expectation they have set for students, but perpetuating negative affect of teachers' expectation can enlarge achievement gap in class. 
Future studies investigating the expectation will remain the same in the next semester are needed to reveal. The negative expectation hold by teachers will give harm for some students. Involving teachers with a different range of teaching experience may also become an interesting focus of the next research studies.

\section{REFERENCES}

Boer, H., Timmermans, A.C., Werf, M. P. C. 2018. The effects of teacher expectation interventions on teachers' expectations and student achievement: narrative review and metaanalysis. Educational Research and Evaluation, 24(5), 180-200

Boser, U., Wilhelm, M., Hanna, R. 2014. The Power of the Pygmalion Effect: Teachers Expectations Strongly Predict College Completion. Center for American Progress, $1-7$

Chang, J. 2011. A Case Study of the "Pygmalion Effect": Teacher Expectations and Student Achievement. International Education Studies. 4(1), 198-201

Isnawati, I., Saukah, A. 2017. Teachers' Grading Decision Making. Teflin Journal. 28(2), 155169

Niari, M., Manousou, E., Lionarakis, A. 2016. The Pygmalion Effect In Distance Learning: A Case Study At The Hellenic Open University. European Journal of Open, Distance and eLearning. 19(1), 36-52

Olivia, N. S. 1991. Teacher Expectations of Students' Performance: a Review of the Research, Early Child Development and Care. 76(1), 27-41

Papageorge, N., Gershenson, S. 2016 Sep 16. Do Teacher Expectations Matter? Brown Center Chalkboard

Wang, M., Chai, J. 2016. The Application of Pygmalion Effect in Classroom Education. International Conference on Arts, Design and Contemporary Education. China: 980-982

Workman, E. 2012. Teacher Expectations of Students. The Progress of Education Reform. 13(6), $1-7$ 